\title{
Effect of ammonium salts on brain metabolism
}

\author{
I. M. JAMES ${ }^{1}$, LINDSAY MACDONNELL, AND C. XANALATOS \\ From the Department of Medicine, Royal Free Hospital, London
}

SYNOPSIS Ammonium acetate (13 m-mol), ammonium bicarbonate (13 m-mol), and ammonium hydroxide $(30 \mathrm{~m}$-mol) were administered intravenously to three separate groups of five dogs. Ammonium acetate and bicarbonate were given over a period of 15 minutes, ammonium hydroxide $\stackrel{\varnothing}{\Omega}$ was given for 30 minutes. In all dogs, after 15 minutes' infusion, the blood ammonia concentration was similar to that found in patients with hepatic coma. When the ammonium hydroxide had been $\vec{\circ}$ given for 30 minutes, lightening of anaesthesia was noted in all dogs studied. At this time blood ammonia values were over $1,000 \mu \mathrm{g} / 100 \mathrm{ml}$ in two animals. Subsequent deepening of anaesthesia was observed after termination of the infusion. In all animals studied there was an increase in cerebral glucose consumption with little change in oxygen utilization. Arterial lactic acid was studied in the group given ammonium bicarbonate and found to increase at the same time as the $\omega_{y}$ increase in glucose utilization. Hyperventilation was precipitated by both acid and alkaline $\infty$ ammonium salts. Lactic acidosis appeared to be the cause rather than the result of the hypero ventilation. The protective effect of hyperventilation on brain metabolism is discussed.

The role of ammonia in the genesis of hepatic coma is still far from clear. Thus, while in hepatic coma there is an elevation of blood ammonia and a reduction in cerebral oxygen utilization, the correlation between these two variables is poor (Fazekas et al., 1956). The infusion of ammonium acetate into dogs was shown some years ago (James et al., 1971) to cause a reduction in cerebral oxygen consumption. However, these experiments were performed in dogs whose ventilatory rate and depth were kept constant throughout and thus compensatory hyperventilation was impossible. Since hyperventilation is common in patients with chronic liver disease (Vanamee et al., 1956) and since the respiratory alkalosis is thought in these circumstances to be compensatory, acting to protect rather than to impair brain function (Posner and Plum, 1966), it seemed important to evaluate the effect of ammonium salts in freely ventilating animals as well as in those in whom the ventilation had been controlled.

\section{METHODS}

The experiments were carried out on 15 mongrel

Address for correspondence: Dr I. M. James, Department of Medicine, Royal Free Hospital, Gray's Inn Road, London, WC1X 8LF. dogs of mean weight $17.5 \mathrm{~kg}$. They were anaesthet ized with sodium pentobarbitone in a dosage of $2 \mathrm{~g}$ $\mathrm{mg}$ per $\mathrm{kg}$ body weight and allowed to breath freely.

The left femoral artery was cannulated with $\underset{a}{\vec{a}} \stackrel{f}{ }$ polyethylene catheter and mean arterial blood pressure was continuously recorded using a Statham P23 AC transducer. Arterial blood samples were obtained from the same source.

A branch of the left femoral vein was similarly $\stackrel{\square}{D}$ catheterized and through this the solution of $\vec{A}$ ammonium acetate in the first group of dogs, and $\frac{9}{3}$ ammonium bicarbonate in the second group, were infused in a total dose of $13 \mathrm{~m}$-mol over a 15 minute period. In the third group of dogs it was planned to infuse ammonium hydroxide at a rate of $1 \mathrm{~m}$-mol per minute for several hours in order to determine the effects of a prolonged infusion. There were five dogs in each group.

Cortical blood flow was measured by the method of Ingvar and Lassen (1962), using intracarotid $ᄋ$ injection of ${ }^{85}$ Krypton. The left common carotid artery was catheterized via the left superior thyroid artery. Craniotomy extending to both sides of the superior sagittal sinus and removal of the dura mater $\sigma$ were carried out in the conventional manner. Radio- N activity was measured over the left parietal region with a Mullard MX 147 Geiger counter of effective window diameter $9 \mathrm{~mm}$. The radioactive gas dis- 
solved in saline was injected slowly into the carotid artery over approximately one minute so that a constant amount of radioactivity monitored over the left parietal region was obtained for 45 seconds. Cortical blood flow was then obtained from the analysis of the first 100 seconds of the ensuing decay curve as suggested by Ingvar and Lassen (1962).

A fine catheter was placed in the superior sagittal sinus in such a way as not to impede flow, but which enabled samples of cortical venous blood to be obtained.

Blood samples for oxygen content, glucose content, lactic acid levels, $\mathrm{pH}$, and $\mathrm{PCO}_{2}$ were taken from the femoral artery as well as from the superior sagittal sinus, thus enabling changes in cortical oxygen and glucose consumption to be obtained.

In the calculation of cortical consumption of oxygen and glucose it was assumed that the superior sagittal sinus drains only cortical blood. There is good anatomical evidence in the dog to justify this assumption (Hegadus and Shackleford, 1965). Furthermore, it was also assumed that flow changes in the portion of cortex measured represented changes in flow in all parts of the cortex draining into the sagittal sinus in the circumstances of these experiments.

Oxygen content was measured directly by an oxygen electrode technique (Linden et al., 1965), and glucose by a glucose oxidase method (Morely et al., 1968). The $\mathrm{pH}$ and $\mathrm{PCO}_{2}$ were measured with the appropriate radiometer electrodes.

Blood ammonia was measured in the ammonium acetate and ammonium hydroxide groups by the method of McCullough (1967) and in the ammonium bicarbonate experiments by the method of Dropsy and Boy (1961) using an autoanalyser and con- tinuous sampling from a small branch of the right femoral artery.

Blood lactic acid levels were estimated in the group of dogs to which ammonium bicarbonate was administered, using the method of Hohorst (1963). The measurements of flow and blood sampling were carried out at the end of each 15 minute period.

\section{RESULTS}

EFFECT OF AMMONIUM ACETATE (Table 1) Absolute control values (mean $\pm S E M)$ were as follows:

Cerebral blood flow

$$
(\mathrm{ml} / 100 \mathrm{~g} / \mathrm{min})
$$$$
109 \cdot 0 \pm 17 \cdot 4
$$

Cerebral oxygen consumption

$$
(\mathrm{ml} / 100 \mathrm{~g} / \mathrm{min})
$$

Cerebral glucose consumption

$$
\text { (mg/100 g/min) }
$$$$
8 \cdot 6 \pm 1 \cdot 0
$$

The administration of ammonium acetate to free ventilated dogs caused a large significant elevation of blood ammonia concentrations. The levels were similar to those found in patients with hepatic coma, and also similar to those levels found when the same dose of ammonium acetate was infused into constantly ventilated animals (James et al., 1971). Within 30 minutes after termination of the infusion these had returned to control levels.

The hyperventilation that occurred during the infusion continued for 15 minutes after the end of the infusion. It was accompanied by a fall in both $\mathrm{PaCO}_{2}$ and cerebral blood flow.

TABLE 1

EFFECT OF INFUSION OF AMMONIUM ACETATE FOR 15 MINUTES ON CEREBRAL BLOOD FLOW, CEREBRAL OXYGEN AND

\begin{tabular}{|c|c|c|c|c|c|}
\hline & \multicolumn{2}{|c|}{ Control period } & \multirow{2}{*}{$\begin{array}{c}\text { Experimental } \\
\text { period } \\
15 \mathrm{~min}\end{array}$} & \multicolumn{2}{|c|}{ Recovery period } \\
\hline & $15 \min$ & $15 \min$ & & $15 \min$ & $15 \min$ \\
\hline $\begin{array}{l}\text { Arterial blood } \mathrm{NH}_{3}(\mu \mathrm{g} / 100 \mathrm{ml}) \\
\text { Cerebral blood flow }(\%) \\
\text { Cerebral oxygen consumption }(\%) \\
\text { Cerebral glucose consumption }(\%) \\
\text { Respiratory rate/min } \\
\mathrm{PaCO}_{2}(\mathrm{mmHg}) \\
\text { Arterial }\left(\mathrm{H}^{+}\right)(\mathrm{n}-\mathrm{mol} / \mathrm{l})\end{array}$ & $\begin{array}{l}113 \pm 7 \\
100 \\
100 \\
100 \\
13 \cdot 7 \pm 2 \cdot 6 \\
39 \cdot 3 \pm 1 \cdot 9 \\
53 \cdot 0 \pm 12 \cdot 4\end{array}$ & $\begin{array}{l}111 \pm 5 \\
102 \cdot 3 \pm 1 \cdot 4 \\
103 \cdot 5 \pm 3 \cdot 4 \\
106 \cdot 0 \pm 9 \cdot 6 \\
14 \cdot 7 \pm 2 \cdot 8 \\
39 \cdot 3 \pm 2 \cdot 3 \\
51 \cdot 0 \pm 11 \cdot 1\end{array}$ & $\begin{array}{c}350 \pm 18 * \\
72 \cdot 0 \pm 3 \cdot 9 \dagger \\
101 \cdot 5 \pm 13 \cdot 8 \\
174 \cdot 8 \pm 22 \cdot 8^{*} \\
27 \cdot 0 \pm 6 \cdot 0 \\
32 \cdot 3 \pm 3 \cdot 7 \\
49 \cdot 8 \pm 11 \cdot 7\end{array}$ & $\begin{array}{c}150 \pm 10^{*} \\
85 \cdot 3 \pm 4 \cdot 6 \dagger \\
101 \cdot 0 \pm 7 \cdot 0 \\
170 \cdot 3 \pm 26 \cdot 1^{*} \\
26 \cdot 3 \pm 7 \cdot 8 \\
34 \cdot 3 \pm 1 \cdot 2 \\
46 \cdot 8 \pm 11 \cdot 5\end{array}$ & $\begin{array}{l}117 \pm 7 \\
97 \cdot 5 \pm 5 \cdot 4 \\
101 \cdot 8 \pm 6 \cdot 3 \\
134 \cdot 0 \pm 20 \cdot 7 \\
24 \cdot 7 \pm 7 \cdot 3 \\
34 \cdot 0 \pm 7 \cdot 8 \\
47 \cdot 3 \pm 11 \cdot 8\end{array}$ \\
\hline
\end{tabular}
GLUCOSE CONSUMPTION, RESPIRATORY RATE, PaCO 2 , AND ARTERIAL HYDROGEN ION CONCENTRATION IN FREE VENTILATED DOGS

* Significantly above control at the $5 \%$ level.

+ Significantly below control at the $5 \%$ level.

Results are mean $\pm \operatorname{SEM}(n=5)$. 
TABLE 2

EFFECT OF INFUSION OF AMMONIUM BICARBONATE FOR 15 MINUTES ON CEREBRAL BLOOD FLOW, CEREBRAL OXYGEN AND GLUCOSE CONSUMPTION, ARTERIAL AND VENOUS LACTIC ACID LEVELS, RESPIRATORY RATE, PaCO $_{2}$, AND HYDROGEN ION CONCENTRATION IN FREE VENTILATED DOGS

\begin{tabular}{|c|c|c|c|c|c|}
\hline & \multicolumn{2}{|c|}{ Control period } & \multirow{2}{*}{$\begin{array}{c}\text { Experimental } \\
\text { period } \\
15 \text { min }\end{array}$} & \multicolumn{2}{|c|}{ Recovery period } \\
\hline & $15 \min$ & $15 \min$ & & $15 \mathrm{~min}$ & $15 \min$ \\
\hline $\begin{array}{l}\text { Arterial blood } \mathrm{NH}_{3}(\mu \mathrm{g} / 100 \mathrm{ml}) \\
\text { Cerebral blood flow }(\%) \\
\text { Cerebral oxygen consumption }(\%) \\
\text { Cerebral glucose consumption }(\%) \\
\text { Arterial lactic acid }(\mathrm{mg} / 100 \mathrm{ml}) \\
\text { Venous lactic acid }(\mathrm{mg} / 100 \mathrm{ml} \\
\text { Respiratory rate } / \mathrm{min} \\
\mathrm{PaCO}_{2}(\mathrm{mmHg}) \\
\text { Arterial }\left(\mathrm{H}^{+}\right)(\mathrm{n}-\mathrm{mol} / \mathrm{l})\end{array}$ & $\begin{array}{l}16 \pm 6 \\
100 \\
100 \\
100 \\
10 \cdot 1 \pm 2 \cdot 4 \\
12 \cdot 1 \pm 2 \cdot 4 \\
12 \cdot 8 \pm 2 \cdot 4 \\
47 \cdot 0 \pm 3 \cdot 8 \\
51 \cdot 2 \pm 1 \cdot 6\end{array}$ & $\begin{array}{c}16 \pm 6 \\
100 \cdot 2 \pm 1 \cdot 8 \\
100 \cdot 6 \pm 0 \cdot 6 \\
101 \cdot 4 \pm 1 \cdot 4 \\
10 \cdot 6 \pm 2 \cdot 3 \\
13 \cdot 1 \pm 2 \cdot 9 \\
11 \cdot 6 \pm 1 \cdot 7 \\
46 \cdot 4 \pm 3 \cdot 5 \\
50 \cdot 2 \pm 3 \cdot 0\end{array}$ & $\begin{array}{l}474 \pm 186^{*} \\
108 \cdot 2 \pm 9 \cdot 3 \\
112 \cdot 2 \pm 5 \cdot 5 \\
155 \cdot 8 \pm 14 \cdot 7^{*} \\
15 \cdot 0 \pm 2 \cdot 5 \\
14 \cdot 7 \pm 2 \cdot 3 \\
17 \cdot 4 \pm 3 \cdot 6 \\
49 \cdot 0 \pm 1 \cdot 8 \\
51 \cdot 9 \pm 4 \cdot 5\end{array}$ & $\begin{array}{c}48 \pm 25 \\
94 \cdot 8 \pm 3 \cdot 1 \\
113 \cdot 2 \pm 6 \cdot 7 \\
96 \cdot 8 \pm 11 \cdot 8 \\
14 \cdot 8 \pm 1 \cdot 7 \\
15 \cdot 4 \pm 2 \cdot 0 \\
18 \cdot 2 \pm 2 \cdot 9 \\
41 \cdot 0 \pm 2 \cdot 4 \\
45 \cdot 7 \pm 3 \cdot 1\end{array}$ & $\begin{array}{c}21 \pm 5 \\
95 \cdot 0 \pm 3 \cdot 2 \\
112 \cdot 6 \pm 8 \cdot 8 \\
105 \cdot 8 \pm 10 \cdot 7 \\
16 \cdot 9 \pm 1 \cdot 5 \\
17 \cdot 5 \pm 2 \cdot 6 \\
17 \cdot 2 \pm 3 \cdot 8 \\
41 \cdot 4 \pm 3 \cdot 4 \\
49 \cdot 3 \pm 2 \cdot 6\end{array}$ \\
\hline
\end{tabular}

* Significantly above control at the $5 \%$ level.

$\uparrow$ Significantly below control at the $5 \%$ level.

Results are mean $\pm \operatorname{SEM}(n=5)$.

TABLE 3

EFFECT OF INFUSION OF AMMONIUM HYDROXIDE FOR 30 MINUTES ON CEREBRAL BLOOD FLOW, CEREBRAL OXYGEN ANB $\infty$ GLUCOSE CONSUMPTION, RESPIRATORY RATE, $\mathrm{PaCO}_{2}$, AND ARTERIAL HYDROGEN ION CONCENTRATION IN FREE VENTILATEË C DOGS

\begin{tabular}{|c|c|c|c|c|c|c|}
\hline & \multicolumn{2}{|c|}{ Control period } & \multicolumn{2}{|c|}{ Experimental period } & \multicolumn{2}{|c|}{ Recovery period } \\
\hline & $15 \mathrm{~min}$ & 15 min & $15 \min$ & $15 \min$ & $15 \mathrm{~min}$ & $15 \mathrm{~min}$ \\
\hline $\begin{array}{l}\text { Arterial blood } \mathrm{NH}_{3}(\mu \mathrm{g} / 100 \mathrm{ml}) \\
\text { Cerebral blood flow }(\%) \\
\text { Cerebral oxygen consumption }(\%) \\
\text { Cerebral glucose consumption }(\%) \\
\text { Respiratory rate per minute } \\
\mathrm{PaCO}_{2}(\mathrm{mmHg}) \\
\text { Arterial }\left(\mathrm{H}^{+}\right) \text {(n-mol/l) }\end{array}$ & $\begin{array}{l}94 \pm 12 \\
100 \\
100 \\
100 \\
9 \cdot 2 \pm 2 \cdot 3 \\
45 \cdot 8 \pm 1 \cdot 9 \\
50 \cdot 2 \pm 1 \cdot 7\end{array}$ & $\begin{array}{r}96 \pm 12 \\
98 \cdot 6 \pm 1 \cdot 6 \\
100 \cdot 6 \pm 1 \cdot 2 \\
103 \cdot 4 \pm 2 \cdot 9 \\
9 \cdot 2 \pm 2 \cdot 4 \\
46 \cdot 8 \pm 1 \cdot 6 \\
50 \cdot 0 \pm 1 \cdot 5\end{array}$ & $\begin{array}{c}443 \pm 39 * \\
94 \cdot 6 \pm 2 \cdot 9 \\
121 \cdot 4 \pm 13 \cdot 6 \\
189 \cdot 6 \pm 34 \cdot 6 * \\
9 \cdot 4 \pm 2 \cdot 3 \\
45 \cdot 8 \pm 0 \cdot 9 \\
45 \cdot 4 \pm 0 \cdot 5 \dagger\end{array}$ & $\begin{array}{l}994 \pm 171^{*} \\
104 \cdot 5 \pm 8 \cdot 7 \\
132 \cdot 5 \pm 11 \cdot 4^{*} \\
198 \cdot 8 \pm 21 \cdot 0^{*} \\
13 \cdot 0 \pm 3 \cdot 3 \\
47 \cdot 0 \pm 2 \cdot 1 \\
45 \cdot 5 \pm 1 \cdot 5\end{array}$ & $\begin{aligned} & 101 \pm 11 \\
& 73 \cdot 4 \pm 7 \cdot 8 \dagger \\
& 72 \cdot 0 \pm 6 \cdot 4 \dagger \\
& 172 \cdot 2 \pm 29 \cdot 4 * \\
& 17 \cdot 6 \pm 3 \cdot 5 \\
& 40 \cdot 6 \pm 1 \cdot 6 \dagger \pm \\
& 49 \cdot 6 \pm 1 \cdot 7\end{aligned}$ & $\begin{array}{l}98 \pm 9 \\
71 \cdot 6 \pm 7 \cdot 0 \dagger \\
92 \cdot 0 \pm 11 \cdot 5 \\
140 \cdot 8 \pm 25 \cdot 6 \\
16 \cdot 2 \pm 2 \cdot 9 \\
38 \cdot 0 \pm 0 \cdot 8 \dagger \\
48 \cdot 2 \pm 1 \cdot 7\end{array}$ \\
\hline
\end{tabular}

- Significantly above control at the $5 \%$ level.

+ Significantly below control at the $5 \%$ level.

Results are mean $\pm \operatorname{SEM}(n=5)$.

There was no significant change in cerebral oxygen consumption but there was a large significant increase in glucose utilization by the brain, which almost returned to control values at the end of the second recovery period.

During the infusion and in the subsequent control periods there was a slight, non-significant fall in arterial hydrogen ion concentration.

EFFECT OF AMMONIUM BICARBONATE (Table 2) Absolute control values (mean \pm SEM) were as follows:

$$
\begin{gathered}
\text { Cerebral blood flow } \\
(\mathrm{ml} / 100 \mathrm{~g} / \mathrm{min})
\end{gathered}
$$

Cerebral oxygen consumption $(\mathrm{ml} / 100 \mathrm{~g} / \mathrm{min})$

Cerebral glucose consumption (mg/100 g/min)

The control ammonia levels were lower with the autoanalyser method than those found pre-ô viously. This discrepancy is unexplained.

The administration of ammonium bicarbonates resulted in the expected increase in arteriat blood ammonia levels. These levels were again similar to those found in patients with hepatico coma.

There was no change in cerebral blood flown during the infusion, but once the infusion was 
terminated a small decrease in cerebral blood flow occurred. This decrease in flow may be due in most animals to hyperventilation and fall of the $\mathrm{PaCO}_{2}$.

The infusion, if anything, caused a slight increase in oxygen consumption by the brain which persisted during the following 30 minutes.

As with ammonium acetate, the ammonium bicarbonate administration resulted in a large increase in glucose utilization by the brain which returned towards control values after the infusion had been turned off.

A small drop in arterial hydrogen ion concentration took place when the animals were hyperventilating during the first recovery period.

Both arterial and venous lactic acid levels increased in all animals during the ammonium bicarbonate infusion and remained so during the following control periods. The arteriovenous difference of lactic acid fell during the period of infusion but, since the arterial concentration was not constant at this time, this arteriovenous difference cannot be taken as a reflection of tissue metabolism (Zierler, 1961).

EFFECT OF AMMONIUM HYDROXIDE (Table 3) Absolute control values (mean $\pm \mathrm{SEM}$ ) were as follows:

Cerebral blood flow

$(\mathrm{ml} / 100 \mathrm{~g} / \mathrm{min})$

Cerebral oxygen consumption $(\mathrm{ml} / 100 \mathrm{~g} / \mathrm{min})$

Cerebral glucose consumption $(\mathrm{mg} / 100 \mathrm{~g} / \mathrm{min})$

$$
\begin{array}{r}
119 \cdot 0 \pm 5 \cdot 0 \\
9 \cdot 3 \pm 0 \cdot 7 \\
12 \cdot 5 \pm 1 \cdot 8
\end{array}
$$

Although it was originally intended that the infusion of ammonium hydroxide should be continued for several hours, it was noticed that after approximately 30 minutes of infusion in the first dog the depth of anaesthesia was rapidly lightening. The infusion was turned off at this time and the animal once more became deeply anaesthetized. No sodium pentobarbitone was required.

Because of this, the period of infusion in the other four dogs was also limited to 30 minutes. In all dogs, towards the end of the 30 minute period it was possible to elicit a conjunctival reflex. Within five minutes or so of discontinuing the infusion the conjunctival reflex was lost.

These high ammonia levels had no effect on cerebral blood flow until after the infusion had been turned off and blood ammonia levels started to drop. There then followed a significant reduction in cerebral blood flow which was accompanied by hyperventilation and a significant fall in $\mathrm{PaCO}_{2}$. These values did not return to control levels within the 30 minute period after the infusion.

The ammonium hydroxide caused a significant increase in oxygen consumption by the brain, but during the 15 minutes after the discontinuation of the infusion, cerebral oxygen uptake fell to below control levels. These then returned towards control values during the second 15 minute recovery period.

A very large increase in cerebral glucose consumption occurred during the administration of the ammonium hydroxide and this increase persisted for 30 minutes after termination of the infusion.

A decrease in arterial hydrogen ion concentration occurred during the administration of the alkaline ammonia solution. This returned to control values in the recovery periods although the animals were hyperventilating at this stage.

\section{DISCUSSION}

The infusion of ammonium acetate, ammonium bicarbonate and ammonium hydroxide for 15 minutes caused an elevation of blood ammonia in the dogs similar to the elevation found in patients with hepatic coma. Levels were also similar to those animals given equivalent doses of ammonium salts reported previously (James et al., 1971). The elevation of blood ammonia obtained during the second period with ammonium hydroxide was considerably higher. Nevertheless, no fall in cerebral oxygen consumption was seen. Indeed, when these high ammonia levels were obtained, 'alerting' responses were observed. These results are consistent with the observations of Schenker et al. (1967) who reported alerting in rats after intraperitoneal injection of ammonia salts.

GLUCOSE-OXYGEN IMBALANCE The infusion of all three ammonium salts caused large increases in cerebral glucose utilization without causing similar increases in oxygen consumption. The elevation of both arterial and venous lactic acid 
levels during the ammonium bicarbonate infusion strongly suggests that the excess glucose is being 'shunted' off to lactate. Unfortunately, it was not possible to calculate lactate production by the brain, since the arterial concentration was not constant over this period. Zierler (1961) has discussed the importance of maintaining a constant arterial concentration of a metabolite when interpreting arteriovenous differences as a reflection of tissue metabolism.

Although all dogs hyperventilated and hyperventilation can lead to lactic acidosis (Eichenholz et al., 1962), it is more likely that lactic acidosis in the present circumstances leads to the hyperventilation, since after the administration of ammonium hydroxide the disturbance in glucose utilization was seen a good 15 minutes before an increase in respiratory rate was noted.

IMPORTANCE OF HYPERVENTILATION This present investigation in free ventilated animals contrasts with that previously reported in ventilated animals (James et al., 1971). When ammonium acetate (13 m-mol) was administered to dogs ventilated at constant rate and depth, a depression in cerebral oxygen consumption was noted, no change resulting in glucose utilization. When the experiment was repeated but the dogs allowed to hyperventilate, glucose utilization increased and oxygen consumption remained unchanged. Thus, whereas a similar glucose oxygen imbalance occurred in both sets of dogs, the inability to hyperventilate appeared to be responsible for the reduction in oxygen utilization in the first group. As demonstrated by Posner and Plum (1960), if the respiratory alkalosis resulting from hyperventilation in patients with encephalopathy is corrected with $5 \% \mathrm{CO}_{2}$, then brain oxygen consumption falls and marked clinical deterioration occurs.

CHANGES IN BLOOD AMMONIA AND BRAIN OXYGEN UTILIZATION One of the main difficulties in ascribing to ammonia a causal role in the genesis of encephalopathy has been the lack of correlation between the elevation of blood ammonia concentration in patients with hepatic coma and the decrease in oxygen consumption. However, it may be that ammonia disturbs intracellular metabolism so that lactic acidosis results and yet for the effects of that intracellular acidosis to be masked by the presence of the ammonia. Ammonia itself is an excellent hydrogen acceptor. When levels of blood ammonia fall, there is presumably an efflux of ammonia from the cell leaving apparent the intracellular acidosis. The fact that brain oxygen consumption fell and hyperventilation occurred in the dogs only after the ammonium hydroxide had been switched off supports this hypothesis. Thus the argument that ammonia cannot affect brain metabolism because there exists a poor correlation between blood ammonia levels and cerebral oxygen consumption in patients with coma becomes irrelevant.

Although a fall in oxygen consumption did $\vec{\circ}$ not occur until very large doses of an ammonium salt had been given, if other factors were present, such as potassium depletion, a drop of oxygen consumption by the brain might have more readily been precipitated.

Total body potassium is low in patients witto liver diseases (Casey et al., 1965) and it has beef shown (Schloerb et al., 1967) that increases i⿱⺈ extracellular $\mathrm{pCO}_{2}$ cause greater increases in tissue hydrogen ion concentration in potassiun deficient animals than in normal animals. It

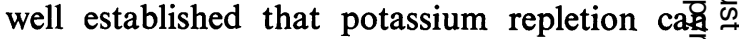
improve patients with hepatic encephalopathy흔 $\vec{\theta}$

The increase in production of lactic acid by $f$ patients with hepatic disease with hyperammonaemia has recently been discussed by Klassen et al. (1969). Stimulation of glycolysis by hyperventilation, local tissue hypoxia, an increase in circulating adrenaline, and a metabolic $\stackrel{\square}{\triangle}$ block caused by ammonia are the possibilities $\overrightarrow{\vec{O}}$ they consider.

The first two possibilities appear to be unlikely to be responsible for the lactic acid production found in the present study. No evidence was found to support or refute the contention that? catecholamines may be implicated. However, $\frac{9}{3}$ there is evidence to suggest that catecholamine effects on brain metabolism are $\mathrm{pH}$ dependent, being potentiated by alkalosis and inhibited by acidosis (Xanalatos and James, 1972).

Klassen et al. (1969) showed in their subjects that, although lactic acid production was increased, fatty acid utilization was normal and ${ }^{\circ}$ they argued that the pathway from acetyl $\mathrm{CoA} N$ into the tricarboxylic acid cycle must therefore be $\mathrm{N}$ normal. They agreed therefore with McKhann? 
and Tower (1961) that interference with the decarboxylation of pyruvate by ammonia would explain the metabolic disturbance Although such a mechanism of action would explain the findings in our present study, so would a preferential shunting of pyruvate to lactate without a block of pyruvate decarboxylation. Since energy requirements of the brain are presumably increased during the 'alerting' which follows ammonium hydroxide infusion, this is perhaps a more likely suggestion.

We thank Professor Sheila Sherlock and Professor Eleanor Zaimis for their continued encouragement and support. This work was supported by a Medical Research Council grant to I.M.J.

\section{REFERENCES}

Bessman, S. P., and Bessman, A. N. (1955). The cerebral and peripheral uptake of ammonia in liver disease with an hypothesis for the mechanism of hepatic coma. Journal of Clinical Investigation, 34, 622-628.

Casey, T. H., Summerskill, W. H., and Orvis, A. L. (1965). Body and serum potassium in liver disease. 1. Gastroenterology, 48, 198-207.

Dropsy, G., and Boy, J. (1961). Détermination de l'ammoniéme. (Méthode automatique par dialyse.) Annales de Biologie Clinique, 19, 313-317.

Eichenholz, A., Mulhausen, R. O., Anderson, W. E., and MacDonald, F. M. (1962). Primary hypocapnia: a cause of metabolic acidosis. Journal of Applied Physiology, 17, 283288.

Fazekas, J. F., Ticktin, H. E., Ehrmantraut, W. R., and Alman, R. W. (1956). Cerebral metabolism in hepatic insufficiency. American Journal of Medicine, 21, 843-849.

Hegedus, S. A., and Shackelford, R. T. (1965). A comparative-anatomical study of the cranio-cervical venous systems in mammals, with special reference to the dog: relationship of anatomy to measurements of cerebral blood flow. American Journal of Anatomy, 116, 375-386.

Hohorst, H.-J. (1963). L-(+)-Lactate. Determination with lactic dehydrogenase and DPN. In Methods of Enzymatic
Analysis, pp. 266-270. Edited by H.-U. Bergmeyer. Academic Press: New York.

Ingvar, D. H., and Lassen, N. A. (1962). Regional blood flow of the cerebral cortex determined by Krypton ${ }^{85}$. Acta Physiologica Scandinavica, 54, 325-338.

James, I. M., Garassini, M., and Larbi, E. (1971). The effect of ammonium salts on cerebral and hind-limb consumption of oxygen and glucose in the ventilated dog. Clinical Science, 41, 403-408.

Klassen, G. A., Aronoff, A., and Karpati, G. (1969). Forearm metabolism in patients with chronic liver disease. Clinical Science, 37, 455-470.

Linden, R. J., Ledsome, J. R., and Norman, J. (1965). Simple methods for the determination of the concentration of carbon dioxide and oxygen in blood. British Journal of Anaesthesia, 37, 77-88.

McCullough, H. (1967). The determination of ammonia in whole blood by a direct colorimetric method. Clinica Chimica Acta, 17, 297-304.

McKhann, G. M., and Tower, D. B. (1961). Ammonia toxicity and cerebral oxidative metabolism. American Journal of Physiology, 200, 420-424.

Morley, G., Dawson, A., and Monks, V. (1968). Guaiacum Method for Blood Glucose Determination Using the Autoanalyser. Meeting of the Association of Clinical Biochemists, Southern Region, University College Hospital, London.

Posner, J. B., and Plum, F. (1960). The toxic effects of carbon dioxide and acetazolamide in hepatic encephalopathy. Journal of Clinical Investigation, 39, 1246-1258.

Schenker, S., McCandless, D. W., Brophy, E., and Lewis, M. S. (1967). Studies on the intracerebral toxicity of ammonia. Journal of Clinical Investigation, 46, 838-848.

Schloerb, P. R., Blackburn, G. L., and Grantham, J. J. (1967). Carbon dioxide dissociation curve in potassium depletion. American Journal of Physiology, 212, 953-956.

Vanamee, P., Poppell, J. W., Glicksman, A. S., Randall, H. T., and Roberts, K. E. (1956). Respiratory alkalosis in hepatic coma. Archives of Internal Medicine, 97, 762-767.

Xanalatos, C., and James, I. M. (1972). Effect of arterial $\mathrm{CO}_{2}$ pressure on the response of cerebral and hind-limb blood flow and metabolism to an isoprenaline infusion in the dog. Clinical Science, 42, 63-68.

Zierler, K. L. (1961). Theory of the use of arteriovenous concentration differences for measuring metabolism in steady and non-steady states. Journal of Clinical Investigation, 40, 2111-2125. 